\title{
The New Tertiary Model and Its Low-Level Impact
}

\author{
Tony Richardson \\ Massey University, Albany, Auckland, New Zealand
}

\author{
t.s.richardson@massey.ac.nz
}

\begin{abstract}
There have been many articles written which describe the changing financial environment currently faced by tertiary institutions. In New Zealand our Universities and Polytechnics have faced a gradual perstudent reduction in government funding over the past decade and, despite the public utterances of ministers of education, there is little evidence that this is anything but a continuing trend. This has pushed institutions towards the so-called "commercialisation of the education sector". It means greater efficiencies in the delivery of courses, greater emphasis on the marketing of popular courses and reductions in the numbers of general and academic staff. The dreaded word "restructuring" has begun to be whispered in the corridors and staff lounges of Universities, a state akin to the whisperings of "downsizing" and "core business concentration" among the true corporates of our economies. Interestingly, this shift in tertiary institution modeling at the macro level has been reflected down at the micro level of individual courses and assessments and it is this low level change which has prompted this paper.
\end{abstract}

\section{Introduction}

The quality of an education "product" is determined by several inter-related factors. For an Information Systems course, some of those factors are:

- Technology resources available to the course

- Student Enrolments

- Student quality

- Teaching staff levels and quality

- Level and quality of teaching assistants/tutors

- Complexity and number of assessments

The course which triggered this paper, is a second year, undergraduate course covering introductory database and implementation. It gives the students a taste of relational theory as well as the practical construction of SQL generated database queries.

\section{Technology Management}

The new University model referred to above places IT services as a separate cost center. This fact imbues the University IT administration function with the same mentality which pervaded corporate IT departments in the 1970s and early 1980s, namely, that centralization of control:-
a) minimises network management,
b) maximises resource utilization,
c) minimises duplication of resources 
d) maximises IT function headcount

This approach has manifested itself in the reduction of specialist computer labs run by individually financed University academic departments and the adoption of large general computer labs, which in most cases, are designed to maximize the number of students per square metre of bench space. Emphasis on resource use optimization has seen an inevitable decline in the ratio of workstations per student and an increase in the number of twenty-four hour access labs. For our introductory database course, the technology availability issue results in an eight hours per week booking for two general labs (sixty workstations) and two additional evenings per assessment.

\section{Student Enrolments}

Government funding changes have seen greater emphasis placed by Universities on increasing student roles and opening tertiary education to a wider market. In other words, placing more "bums on seats". This approach has been successful, particularly in the computer related disciplines. However, cost related efficiencies have seen gradual reductions in the staff: student ratio.

\section{Student Quality}

A wider market has translated into a reduction, or in some cases elimination, of University entry qualifications. Increasingly we see students with deficiencies in basic mathematics, communications and English skills, which, when coupled with the frantic pace of the Semester system means academically weaker students have less time to succeed than their academically superior counterparts of ten years earlier. Add to this mix the fact that the approaches associated with Object-Oriented techniques in a distributed environment are intrinsically more complex than the structured-programming equivalents of a decade ago and it is no surprise that one sees struggling students, declining academic results and dissatisfaction with the outputs of Universities among potential student employers.

\section{Teaching Staff Levels and Quality}

New Zealand is predominantly an economy based around agricultural commodities and in recent years the New Zealand government has followed a strategy for growth centred on a weak currency and high exports. During the same timeframe, the remuneration packages of University staff have not kept pace with inflation and, as a consequence, New Zealand Universities find it exceptionally difficult to recruit the staff members they would like to recruit from overseas. Again this feeds into a cycle of reducing contact time per student and increasing administration time per course. More teaching and administration means less research and an inevitable decline in quality as staff struggle to keep up with a rapidly changing IT environment.

\section{Teaching Assistants and Tutors}

The growth in IT commercial recruitment and the paucity of funds available to Universities to pay market rate salaries to teaching assistants and tutors had led to a shortage of such staff. Inevitably, the staff which are in place are overworked and suffer the same lack of time for scholarship as the academics.

\section{Complexity and Number of Assessments}

As a consequence of the above, assessing students via traditional paper assignments has given way to practical and objective tests. The staff: student ratio and complexity of the subject matter has precluded the use of the traditional and lengthy marking, policing and administrative procedures. Even so, the numbers of assessments is being reduced and a higher percentage of total course assessment given over to a 
one-off, end of course examination. The opportunity for "learning by doing" and "frequent feedback", goals which are accepted as pedagogically laudable, are being sacrificed to new goals of "throughput" and "retention".

\section{The Market Demands}

From a student perspective the new model offers a double-edged sword. On the one hand, increased access to tertiary education means that those students who perform badly at school are no longer "branded for life", but now have the opportunity to start education again at University. On the other hand, of course, is the perceived downgrading by the general public of a Bachelor's degree. In the USA, it is increasingly the case that a Post-Graduate qualification is seen as de-rigeur for jobs which, not long ago, graduates would have been eligible for.

The tertiary institutions, by applying the new model, have compounded this perception by contorting grades and manipulating pass-rates. As a marketing tool, the likelihood of emerging with an A+ average has much more impact than the certainty of failure if required standards are not met. In New Zealand, as in most other countries, the prize of full fee-paying overseas students is far too valuable to lose and, as a consequence, pressure is bought to bear on course leaders to "tow the line", to structure grades in accordance with the institution's statistical guidelines. In other words, to pass poorly performing students for the greater financial good of the institution.

\section{Winners and Losers}

University vice-chancellors can still be heard using phrases such as "centre of excellence", "educational integrity", "major contributor to research in the field" and so on. But these phrases hark back to the original concept of a University and, certainly in New Zealand, do not reflect the current model at all.

The current model places a University as a profit-making entity within the education sector. To "win", a University must make more money than it spends by delivering tertiary education programs and leveraging any research outputs from it's staff in the form of spin-off ventures.

Within this framework, undergraduate student intakes tend to want more for less and are increasingly litigious if deficiencies or loopholes are found in the product provided for their consumption. To "win" a student must emerge from University with grades which have interview-enabling currency.

Government "wins" if Universities become self-financing entities, but operate under a government charter which constrains their activities.

\section{IT and Education}

In the environment described above, information technology can be used to eliminate several consequent ills and reduce the effects of others. While other authors have suggested how IT can improve the quality of education, IT is now being used to stem the decline in quality and reduce the administrative overheads which are a consequence of political and economic decision-making.

Down at the course level, software is being designed more with problem-solving as a goal than with innovation and technological advancement in mind.

Courses now use software-based assessments as:-

\section{1) A means to combat plagiarism.}

Anecdotal evidence suggests the wider the spectrum of student abilities within a course enrollment the greater the incidence of plagiarism. The competition for high grades being what it is, this should come as 
no surprise. However, the Internet, with its vast array of information and "help" for students makes the creation of submitted work via the copy and paste buttons even easier and the successful prosecution of the culprit more and more problematic.

\section{2) A data logging mechanism}

Systems such as WebCT are being used to track the time spent by students during on-line assessments and to monitor their performance, provide feedback and provide evidential data in the case of appeal for grade reconsideration.

\section{3) Automatically mark assessments}

The deskilling or elimination of assessment marking can significantly reduce the workload faced by academic staff. The use of software tends to make marking more arbitrary but does provide a means to provide rapid feedback and quick turnaround of assessment submissions. On the whole experience with automated marking has shown its worth in some applications, particularly those such as algorithm programming, database queries, systems analysis notations and so on.

\section{4) En-mass delivery and assessment}

Software is now used as the major tool in dealing with large numbers of students, both for assessments, delivery of course material, means of contact and general administration. A single course controller can now cope with several thousand students if the course is structured correctly around computer mediated communication.

Note that the above four points are not utilising IT as a means to improve the learning environment, but as a necessary tool to prevent a rapid decline in quality and to facilitate the teaching and administration of larger and larger class enrollments.

There are of course some positive side-effects, some courses do use IT as a means to provide students with more comprehensive content. The use of streamed video, audio and other web-based technologies have given students easier access to richer leaning environments, which, some would argue, inevitably raise standards and graduate quality.

\section{Discussion Topics}

How can a university survive long term if it pursues an open-door policy on enrollments?

If student demand for post-graduate courses is low, is the downgrading of bachelor's degrees in order to boost the value of post-graduate qualifications amongst employers a legitimate University practice?

Is it time to change the common perception of Universities as "dreaming spires" into a less romantic one of players within the education industry?

Does idealism have any role to play in tertiary education? 